\section{Kleiner Grenzverkehr}

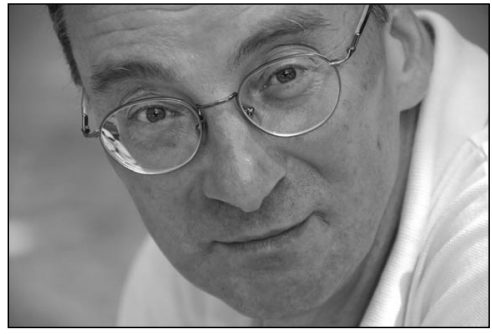

Foto: Petra Schmucker, Frankfurt am Main
Die lange beklagten Grenzen zwischen Gesundheitswesen und Sozialwesen in Deutschland sind noch lange nicht verschwunden, aber sie werden immer durchlässiger. Dazu hat nicht zuletzt die steigende Dominanz der Pflege in Sozialpolitik und Sozialwirtschaft beigetragen. Das "Gesetz zur Stärkung des Wettbewerbs in der gesetzlichen Krankenversicherung ", die Gesundheitsreform 2007, fördert diesen kleinen Grenzverkehr zwischen den beiden ehemals strikt getrennten Arbeitsfeldern weiter.

Die Beiträge in diesem Heft beleuchten die Chancen und die Gefahren der neuesten Gesundheitsreform, deren Inkrafttreten sich über mehrere Jahre erstreckt. Rainer Brückers von der Arbeiterwohlfahrt listet die bereits jetzt erkennbaren Erfolge des Gesetzeswerkes auf: Mehr als 100.000 Personen, die vor der Reform keinen Versicherungsschutz hatten, haben nun wieder eine Krankenversicherung. Die Wohlfahrtsverbände haben auf diese Option mit ihren Möglichkeiten im direkten Kontakt mit betroffenen Menschen intensiv hingewiesen. Auch die Stärkung der Vorsorge- und Rehabilitationsmaßnahmen für Mütter, Väter und Kinder, die seit letztem Jahr gesetzliche Pflichtleistungen der Kassen geworden sind, ist für viele Familien eine deutliche Verbesserung. Kritisch beleuchtet Brückers den geplanten Gesundheitsfonds: Für die Krankenkassen seien auch nach der Reform die einkommensstarken und gesunden Mitglieder attraktiver als chronisch Kranke mit geringen Einkünften. Der mit der Gesundheitsreform beabsichtigte Wettbewerb zwischen den Kassen laufe entsprechend ins Leere.

Wie soziale Leistungserbringer die Möglichkeiten der Gesundheitsreform nutzen können, zeigt Prof. Dr.

Roland Schmidt von der Fachhochschule Erfurt, beispielsweise im Verbund mit anderen Anbietern innerhalb der Integrierten Versorgung.

Gerhard Pfannendörfer - Chefredaktion -

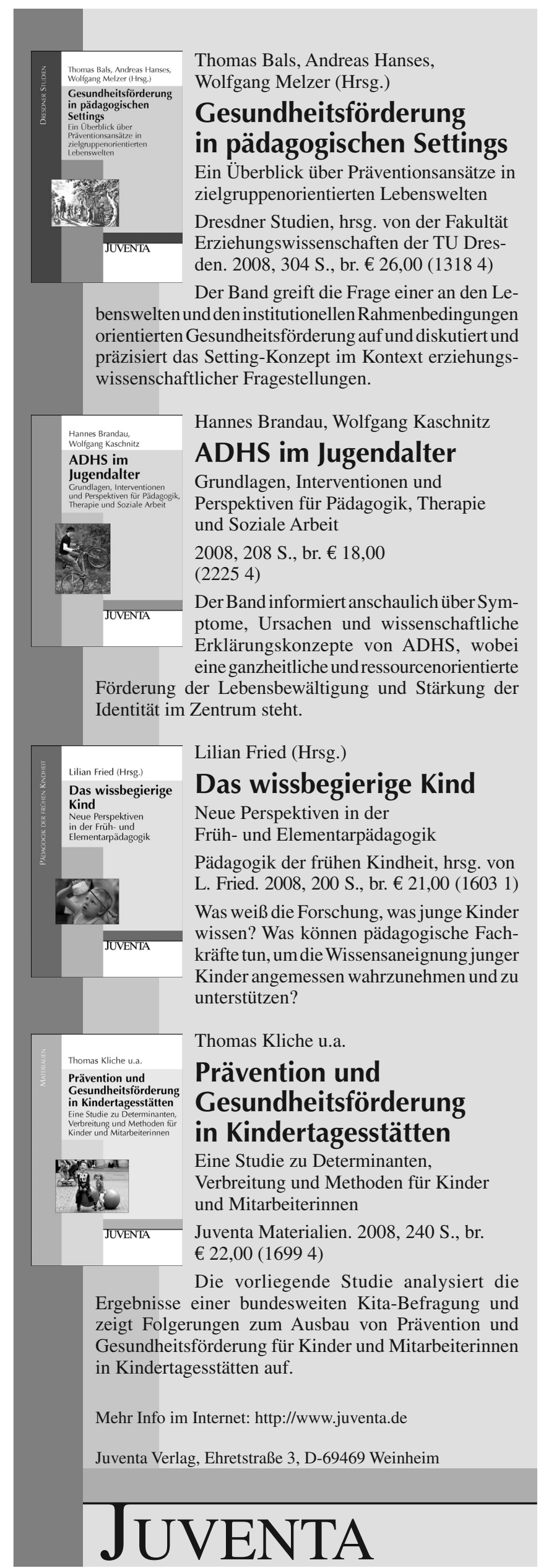

